Tropical Journal of Pharmaceutical Research September 2020; 19 (9): 1797-1805

ISSN: $1596-5996$ (print); 1596-9827 (electronic) (C) Pharmacotherapy Group, Faculty of Pharmacy, University of Benin, Benin City, 300001 Nigeria.

\title{
Enhancement of solubility and dissolution rate of ebastine fast-disintegrating tablets by solid dispersion method
}

\author{
Nayyer Islam ${ }^{1}$, Muhammad Irfan ${ }^{1 *}$, Nasir Abbas², Haroon Khalid Syed', \\ Muhammad Shahid Iqbal $^{3}$, Ikram ullah Khan'1, Akhtar Rasul', Sana Inam ${ }^{1}$, \\ Amjad Hussain ${ }^{2}$, Noor ul Amin Mohsin ${ }^{4}$, Mohammad Sohail Arshad ${ }^{5}$, Mohsin \\ Alí \\ ${ }^{1}$ Department of Pharmaceutics, Faculty of Pharmaceutical Sciences, GC University, Faisalabad, ${ }^{2}$ University College of \\ Pharmacy, University of the Punjab, Lahore, Pakistan, ${ }^{3}$ Department of Clinical Pharmacy, College of Pharmacy, Prince Sattam \\ bin Abdulaziz University, Alkharj, Kingdom of Saudi Arabia, ${ }^{4}$ Department of Chemistry, Faculty of Pharmaceutical Sciences, GC \\ University Faisalabad, ${ }^{5}$ Department of Pharmacy, Bahauddin Zakriya University, Multan, ${ }^{6}$ Department of Pharmacology, Faculty \\ of Pharmaceutical Sciences, GC University, Faisalabad, Pakistan
}

*For correspondence: Email: manipharma@yahoo.co.uk; Tel: 0092-334-9392369

Sent for review: 24 April 2020

Revised accepted: 20 August 2020

\begin{abstract}
Purpose: To investigate the efficiency of different solubilizing agents in improving solubility as well as dissolution rate of ebastine (a BCS class II drug) by incorporating prepared solid dispersion into fast disintegrating tablets.

Method: The solubility of ebastine was determined in distilled water, lipids and solubilizing agents. Subsequently, the binary solid dispersions were prepared by kneading method using varying weight ratios of ebastine and solubilizing agents. The solid dispersions were then incorporated into fast disintegrating tablets (SD-FDT). Central composite rotatable design (CCD) was used to determine the impact of super disintegrating agents on disintegration time and friability of tablets. The solubility and dissolution rate of developed SD-FDT were compared with a marketed brand. The solid dispersion particles were characterized by Fourier-transform infrared spectroscopy (FTIR), differential scanning calorimetry (DSC), powder x-ray diffraction (P-XRD) and scanning electron microscopy (SEM).

Results: The saturated solubility of pure ebastine in water was $0.002 \pm 0.041 \mathrm{mg} / \mathrm{ml}$ while the aqueous solubility of EBT/poloxamer solid dispersion SET3 $(P)$ was $0.018 \pm 2.510 \mathrm{mg} / \mathrm{ml}$; on the other hand, EBT/soluplus solid dispersion SET1(S) has an aqueous solubility of $0.242 \pm 1.390 \mathrm{mg} / \mathrm{ml}$. Within 30 min, drug release was $14.00 \pm 1.77,78.00 \pm 2.31$ and $98.70 \pm 2.54 \%$ from pure EBT, SET3 $(P)$ and SET1(S), respectively.

Conclusion: The solubility and dissolution rate of ebastine has been successfully enhanced by incorporating its solid dispersion in fast-disintegrating tablets (SD-FDT).
\end{abstract}

Keywords: Ebastine, Solid dispersion, Poloxamer 188, Soluplus, Solubility, Dissolution

This is an Open Access article that uses a fund-ing model which does not charge readers or their institutions for access and distributed under the terms of the Creative Commons Attribution License (http://creativecommons.org/licenses/by/4.0) and the Budapest Open Access Initiative (http://www.budapestopenaccessinitiative.org/read), which permit unrestricted use, distribution, and reproduction in any medium, provided the original work is properly credited.

Tropical Journal of Pharmaceutical Research is indexed by Science Citation Index (SciSearch), Scopus, International Pharmaceutical Abstract, Chemical Abstracts, Embase, Index Copernicus, EBSCO, African Index Medicus, JournalSeek, Journal Citation Reports/Science Edition, Directory of Open Access Journals (DOAJ), African Journal Online, Bioline International, Open-J-Gate and Pharmacy Abstracts

\section{INTRODUCTION}

Solubility is a physicochemical feature that relies on a variety of physical and chemical variable of drugs. Solubility and dissolution rate can be improved by controlling these variables [1]. The addition of different solubilizing agents may change the nature of crystals as well as bonding 
forces in crystal lattice leading to change in solubilization behavior of the drug $[2,3]$. Solubility has direct relation with dissolution rate and bioavailability of drug molecule [4]. Thus, improved solubility is required to enhance drug absorption and bioavailability [5].

Solid dispersion (SD) is an effective strategy used to increase the solubility of poorly soluble drugs [6]. For the production of solid dispersion expensive machines and toxic vehicles are not required. Kneading method is the simplest and most efficient method used for the preparation of solid dispersion. As ebastine is thermolabile drug, thus solid dispersion is most suitable system for product development. Such solid dispersions improve the therapeutic efficiency of poorly soluble drugs [7].

The incorporation of solubilizing agents in SD creates the micellar environment, reduce surface tension and maintain thermodynamic equilibrium in the solution state [8]. The presence of solubilizing agents converts crystalline drug molecules to amorphous form in solid state by improving solubility, dissolution rate and eventually bioavailability of drug [9].

Ebastine is a selective, non-sedative $H_{1}$ antihistamine that belongs to Biopharmaceutics Classification System (BCS class II). It is available as a white crystalline powder with molecular weight of $469.66 \mathrm{~g} / \mathrm{mol}$ and a very low aqueous solubility $\left(6.47 \mathrm{e}^{-05} \mathrm{mg} / \mathrm{mL}\right)$. The melting point $\left(\mathrm{T}_{\mathrm{m}}\right)$ of ebastine is $86{ }^{\circ} \mathrm{C}$ and partition coefficient (LogP) is 6.8. The physiochemical properties clearly depict the high hydrophobic nature of drug that could be possible reason of low aqueous solubility. The pharmacokinetic parameters of EBT do not change with multiple doses [10]. It is necessary to develop the drug delivery system to enhance the solubility and dissolution rate.

Previously,_various methods have been used to improve the bioavailability of ebastine, such as the use of hydrophilic materials in orodispersible films and nanoparticles[11]. The solubilizing agents (poloxamer-188 and soluplus) have good absorption properties and could advantageously be used for formulating solid dispersions to get promising results [12]. Many excipients such as poloxamer 188, oleic acid and Soluplus have not yet been thoroughly tested to enhance the physicochemical properties of ebastine. The goal of this research was therefore to improve the solubility and dissolution of ebastine by preparing solid dispersion loaded fast disintegrating tablets (SD-FDT) using selected polymers and solubilizing agents.

\section{EXPERIMENTAL}

Ebastine was purchased from Simz Pharmaceuticals, Lahore, Pakistan. Poloxamer 188 was a gift by Gattefosse, France. Polyvinyl caprolactam-polyvinyl acetate-polyethylene glycol graft copolymer (Soluplus ${ }^{\circledR}$ ) was generously provided by BASF, Germany. Tween 80, castor oil, spans and coconut oil were purchased from Revlon chemical, Lahore, Pakistan. Oleic acid was a gift by Zibo Fengsen, China. All other materials were of pharmaceutical grade and were used as received.

\section{Selection of suitable wavelength and solvent for ebastine analysis}

For the selection of a suitable solvent, the drug stock solutions were prepared in pharmaceutical solvents $(0.1 \mathrm{~N} \mathrm{NaOH}$, distilled water, methanol and $0.1 \mathrm{~N} \mathrm{HCl}$ ). Further dilutions were carried out with respective solvents. The suitable wavelength for analysis was selected on a UV spectrophotometer (Shimadzu, UV 2600 series, Japan) by scanning the solution of appropriate concentration between 200 to $400 \mathrm{~nm}$ UV spectrum ranges. After selection of suitable wavelength, the absorbance of drug solution with different concentrations of $5,10,15,20,25,30$, $35,40,45$ and $50 \mu \mathrm{g} / \mathrm{ml}$ were recorded[13]. Similarly, the absorbance of poloxamer 188, tween 80 , oleic acid and soluplus was noted at the selected wavelength in specific media to check for possible interference of excipients.

\section{Solubility study of ebastine in water and solubilizing agents}

The solubility of ebastine in distilled water, poloxamer 188, soluplus, oleic acid, castor oil, coconut oil and tween 80 was determined by shake flask method. After accurately weighing, $200 \mathrm{mg}$ of ebastine was transferred into a $50 \mathrm{ml}$ capacity conical flask. The volume of flask was made up to $10 \mathrm{ml}$, capped and placed on a Heidolph Unimax Shaker (Unimax 1010) using $100 \mathrm{rpm}$ at $37^{\circ} \mathrm{C}$ temperature for $48 \mathrm{~h}$. Milli pore filter $(0.45 \mu \mathrm{m})$ was used for solution filtration and absorbance was recorded using a UV spectrophotometer at $252 \mathrm{~nm}$ wavelength (Shimadzu, UV 2600 series, Japan) [14].

\section{Preparation of solid dispersions (SD)}

The different solid dispersion formulations were prepared by using kneading method. Poloxamer 188, Soluplus, tween 80 and oleic acid, were used in different $\mathrm{w} / \mathrm{w}$ ratio with ebastine in the fabrication of formulations (Table 1). The amount of solubilizing agents was used in varying ratio to 
check their effect on solubility of ebastine. The solid dispersions, which yielded maximum increase in solubility, were further used for the development of solid dispersion of fast disintegrating tablets (SD-FDT)[15].

\section{Preparation of SD-FDT}

Expert design (stat-ease incorporation, version 12) was used to design different formulation compositions for the optimization of ebastine SDFDT. The method followed was central composite rotatable design. The description of formulation is mentioned in Table 2. The avicel $\mathrm{pH}-102$, lactose, crospovidone and magnesium stearate were weighed, sieved and blended in a mortar and pestle. Round shaped tablets were prepared on a tablet rotary press machine using $8 \mathrm{~mm}$ plain punches by direct compression. The pre- and post-compression evaluation of physical mixture of powder and tablets was also performed [16].

\section{Experimental design and optimization of SD- FDT}

The disintegration time and friability was studied as responses and concentration of crospovidone and sodium starch glycolate as variable using quadratic polynomial equation in regression analysis. The lower limit of cross-povidone and sodium starch glycolate was kept at $0.58 \%$ while upper limit was maintained at $3.41 \%$ for both factors. The design expert generated different combination of super-disintegrants based on the lowest concentration of super-disintegrants to optimize suitable formulation for the best disintegration time and lowest friability. The program proposed formulations were prepared to find the optimum design (Table 3)[17].

Table 1: Solid dispersion formulations of ebastine

\begin{tabular}{|c|c|c|c|c|c|c|c|c|c|c|c|}
\hline SD code & Drug & : Carrier & SD code & Drug & : Carrier & SD code & Drug & : Carrier & SD code & Drug & : Carrier \\
\hline aDPE1 & 1 & $: 0.25$ & bDSE1 & 1 & $: 0.25$ & 'DTE1 & 1 & $: 0.25$ & ${ }^{\mathrm{d} D O E 1}$ & 1 & $: 0.25$ \\
\hline DPE2 & 1 & $: 0.5$ & DSE2 & 1 & $: 0.5$ & DTE2 & 1 & $: 0.5$ & DOE2 & 1 & $: 0.5$ \\
\hline DPE3 & 1 & $: 0.75$ & DSE3 & 1 & $: 0.75$ & DTE3 & 1 & $: 0.75$ & DOE3 & 1 & $: 0.75$ \\
\hline DPE4 & 1 & $: 1$ & DSE4 & 1 & $: 1$ & DTE4 & 1 & $: 1$ & DOE4 & 1 & $: 1$ \\
\hline
\end{tabular}
ebastine and tween 80 , dsolid dispersion of ebastine and oleic acid

Table 2: Composition of ebastine SD-FDT

\begin{tabular}{lcccccc}
\hline \multirow{2}{*}{ Code } & \multicolumn{5}{c}{ Weight (mg per tablet) } & \\
\cline { 2 - 6 } & Ebastine & Avicel pH102 & Lactose & Crospovidone & $\begin{array}{c}\text { Sodium starch } \\
\text { glycolate }\end{array}$ & $\begin{array}{c}\text { Magnessium } \\
\text { stearate }\end{array}$ \\
\hline SET1 (P) & 20 & 102 & 36.8 & 5.1 & 5.1 & 1 \\
SET2 (P) & 20 & 102 & 42.6 & 1 & 3.4 & 1 \\
SET3 (P) & 20 & 102 & 37.8 & 5.8 & 3.4 & 1 \\
SET4 (P) & 20 & 102 & 40.2 & 3.4 & 3.4 & 1 \\
SET5 (P) & 20 & 102 & 40.2 & 1.7 & 5.1 & 1 \\
SET6 (P) & 20 & 102 & 40.2 & 3.4 & 3.4 & 1 \\
SET7 (P) & 20 & 102 & 38.5 & 5.1 & 1.7 & 1.7 \\
SET8 (P) & 20 & 102 & 43.6 & 1.7 & 1 & 1 \\
SET9 (P) & 20 & 102 & 42.6 & 3.4 & 5.8 & 1 \\
SET10 (P) & 20 & 102 & 37.8 & 3.4 & 5.1 & 1 \\
SET1 (S) & 20 & 102 & 36.8 & 5.1 & 3.4 & 1 \\
SET2 (S) & 20 & 102 & 42.6 & 1 & 3.4 & 1 \\
SET3 (S) & 20 & 102 & 37.8 & 5.8 & 3.4 & 1 \\
SET4 (S) & 20 & 102 & 40.2 & 3.4 & 5.1 & 1 \\
SET5 (S) & 20 & 102 & 40.2 & 1.7 & 3.4 & 1 \\
SET6 (S) & 20 & 102 & 40.2 & 3.4 & 1.7 & 1 \\
SET7 (S) & 20 & 102 & 38.5 & 5.1 & 1.7 & 1 \\
SET8 (S) & 20 & 102 & 43.6 & 1.7 & 5.8 & 1 \\
SET9 (S) & 20 & 102 & 42.6 & 3.4 & 3.4 & 1 \\
SET10 (S) & 20 & 102 & 37.8 & & & 1 \\
\hline
\end{tabular}

Table 3: Optimization of SD-FDT formulations 


\begin{tabular}{lccc}
\hline \multirow{2}{*}{ Variable } & \multicolumn{2}{c}{ Constraint } \\
\cline { 2 - 4 } Conc. of cross-povidone (\%) & Goal & Lower limit & Upper limit \\
\hline Conc. of sodium starch glycolate (\%) & In range & -1 & 1 \\
Disintegration time (min.) & In range & -1 & 1 \\
Friability (\%) & In range & 2 & 8 \\
\hline
\end{tabular}

\section{Dissolution studies}

Drug release studies from pure drug and SDFDT were performed using USP paddle apparatus. The dissolution media $(0.1 \mathrm{NHCl})$ was taken in $900 \mathrm{ml}$ vessel. The rotation and temperature of apparatus were set at $50 \mathrm{rpm}$ and $37 \pm 0.5{ }^{\circ} \mathrm{C}$, respectively. Samples were collected at pre-defined time points of $5,10,15$, $20,25,30,35,40,45$ minutes. The samples were filtered, diluted and finally analyzed using a UV spectrophotometer at $252 \mathrm{~nm}$ wavelength. Samples were run as triplicate.

\section{FTIR studies}

The FTIR spectra of ebastine, individual excipients, physical mixture and optimized formulation were obtained by using Agilent Cary630 FTIR spectrometer. Samples were scanned between 4000 and $400 \mathrm{~cm}^{-1}$ at fixed frequency and resolution [18].

\section{XRD analysis}

Samples of ebastine, physical blend and of optimized formulations were run on x-ray diffractometer (JDX-3532 JEOL, Japan) between $2^{\circ}$ and $50^{\circ}$ (2theta) to determine any structural change in formulation. The crystallinity or amorphous nature of the drug was evaluated from the obtained XRD graphs.

\section{DSC analysis}

The determination of melting and phase change behavior in the ingredients was determined by using differential scanning calorimeter (Perkin
Elmer, DSC-8000, USA). The DSC of EBT and (SET1(S) SD-FDT was performed at temperature range between 25 to $400{ }^{\circ} \mathrm{C}$. The scanning speed of $10{ }^{\circ} \mathrm{C} / \mathrm{min}$ and nitrogen gas flow of 100 $\mathrm{ml} / \mathrm{min}$ were fixed for all samples. The DSC samples were scan at heating rate of $10^{\circ} \mathrm{C} / \mathrm{min}$ under nitrogen purging.

\section{RESULTS}

\section{Selected suitable wavelengths and solvent for ebastine analysis}

The sharp peak seen at $252 \mathrm{~nm}$ in methanol was selected for further analysis. Thus, methanol was selected as suitable solvent for initial dissolving the drug and further dilutions were made in $0.1 \mathrm{~N}$ $\mathrm{HCl}$ for preparing standard curve. In order to make standard curve, the different concentrations of $5,10,15,20,25,30,35,40,45$ and $50 \mu \mathrm{g} / \mathrm{mL}$ of ebastine were prepared and absorbance was recorded at $252 \mathrm{~nm}$ on a UVspectrophotometer to draw a linear curve between concentration and absorbance. Furthermore, the absorbance of soluplus, poloxamer, tween 80 and oleic acid was negligible at $252 \mathrm{~nm}$ which clearly shows no interference in absorbance of ebastine by these excipients.

\section{Solubility of ebastine}

The solubility of ebastine in distilled water was only 0.002 whereas it was 0.018 and 0.242 $\mathrm{mg} / \mathrm{ml}$ of SET3 (P) and SET1(S), respectively. Furthermore, the solubility of ebastine from SDFDT was also profoundly improved (Table 4).

Table 4: Solubility of pure drug and SD-FDT

\begin{tabular}{lccc}
\hline Code & Solubility $(\mathbf{m g} / \mathbf{m l})$ & Code & Solubility $(\mathbf{m g} / \mathbf{m l})$ \\
\hline SET1 (P) & 0.018 & SET1 (S) & 0.242 \\
SET2 (P) & 0.01 & SET2 (S) & 0.178 \\
SET3 (P) & 0.018 & SET3 (S) & 0.229 \\
SET4 (P) & 0.011 & SET4 (S) & 0.221 \\
SET5 (P) & 0.08 & SET5 (S) & 0.194 \\
SET6 (P) & 0.011 & SET6 (S) & 0.216 \\
SET7 (P) & 0.011 & SET7 (S) & 0.198 \\
SET8 (P) & 0.06 & SET8 (S) & 0.087 \\
SET9 (P) & 0.08 & SET9 (S) & 0.142 \\
SET10 (P) & 0.014 & SET10 (S) & 0.224 \\
Pure drug & 0.002 & & \\
\hline
\end{tabular}


Table 5: Regression data for responses

\begin{tabular}{lcccccc}
\hline Quadratic model & $\mathbf{R}^{\mathbf{2}}$ & $\begin{array}{c}\text { Adjusted } \\
\mathbf{R}^{\mathbf{2}}\end{array}$ & $\begin{array}{c}\text { Predicted } \\
\mathbf{R}^{\mathbf{2}}\end{array}$ & $\begin{array}{c}\text { Adeq } \\
\text { Precision }\end{array}$ & $\begin{array}{c}\text { Std. } \\
\text { Dev. }\end{array}$ & C.V. \% \\
\hline Disintegration time & 0.967 & 0.9258 & 0.7655 & 13.8411 & 0.015 & 5.77 \\
Friability & 0.9959 & 0.9908 & 0.9708 & 38.6088 & 0.0518 & 2.69 \\
\hline
\end{tabular}

\section{Experimental design}

The results of responses were put to trial runs. The quadratic model was obtained for the dependent variable based on the best fitted observations. The coefficient of correlation was near to 1 . The values of predicted and adjusted $\mathrm{R}^{2}$ were in close agreement to each other (Table 5 ). The difference of predicted and adjusted $R^{2}$ was found less than 0.2 and signal to noise ratio of 13.841 was achieved. The $F$ value of model was 23.46 and $p$-value was less than 0.05 which means applied model was significant.

The relationship between variable factors and responses were expressed in Eqs 1 and 2.

$$
\begin{gathered}
Y_{1}=\beta_{0}+\beta_{1} X_{1}+\beta_{2} X_{2}+\beta_{12} X_{1} X_{2}+\beta_{11} X_{1}^{2}+\beta_{22} X_{2}^{2} \\
D T=0.2500+0.0402 X_{1}+0.042 X_{2}+0.0083 X_{1} X_{2}+0.0062 X_{1}^{2}+0.0062 X_{2}^{2} \\
\text { Frdabllty }=1.67-0.3666 X_{1}-0.4086 X_{2}+0.0652 X_{1} X_{2}+0.1784 X_{1}^{2}+0.1510 X_{2}^{2}
\end{gathered}
$$

\section{Response surface evaluation}

The 2D and 3D graphs were presented to show the influence of variables on disintegration time and friability characteristics of SD-FDT (Figure 1 and Figure 2). The RSM graphs in Figure 1 illustrated the impact of crospovidone and sodium starch glycolate on the disintegration time of SD-FDT. The green region in the graph shows that optimum outcomes were derived from the cumulative effects of both cross-povidone and sodium starch glycolate. On the other hand, the RSM graphs in Figure 2 revealed that friability was increased with the usage of higher concentrations of super-disintegrants in SD-FDT. Minimum friability was obtained when the concentration of sodium starch glycolate and cross-povidone reached equivalent to $1.5 \%$. Optimized results of disintegration time and friability were obtained with a $2 \%$ inclusion of super-disintegrants in SD-FDT.

\section{Dissolution results of ebastine}

The release profile of pure ebastine, prepared SD-FDT (SET1(S), SET3 (P) and MPK (commercial product) in $0.1 \mathrm{NHCl}(\mathrm{pH} \mathrm{1.2)}$ are shown in Figure 3. Importantly, the dissolution rate from the solid dispersions prepared using soluplus and ploxamer 188 was faster as compared to the marketed product as well as from the pure drug.

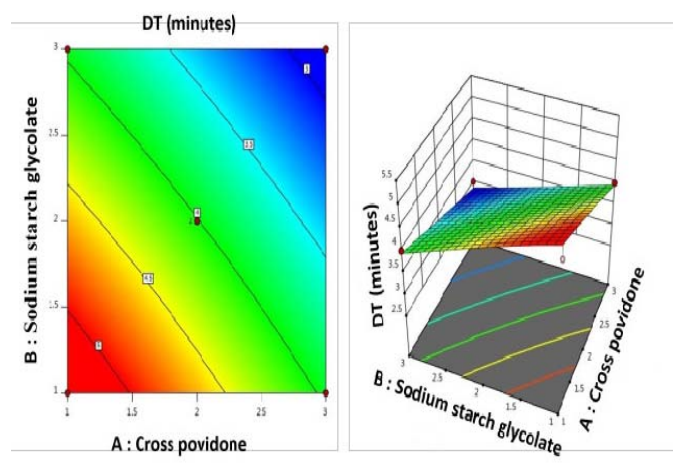

Figure 1: Graphs of RSM displaying impact of solid dispersion on disintegration time of SD-FDT.

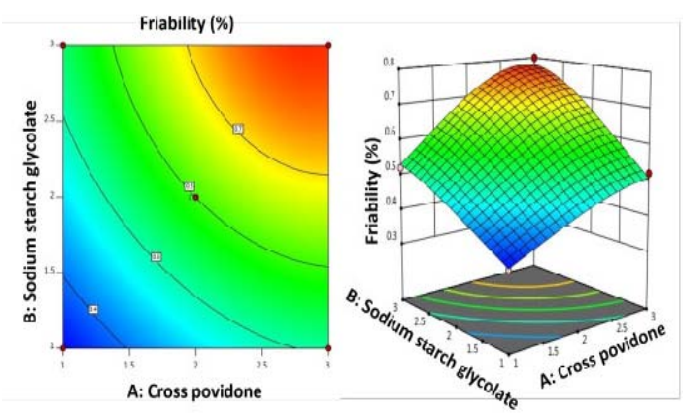

Figure 2: Graphs of RSM presenting impact of solid dispersion on friability of SD-FDT

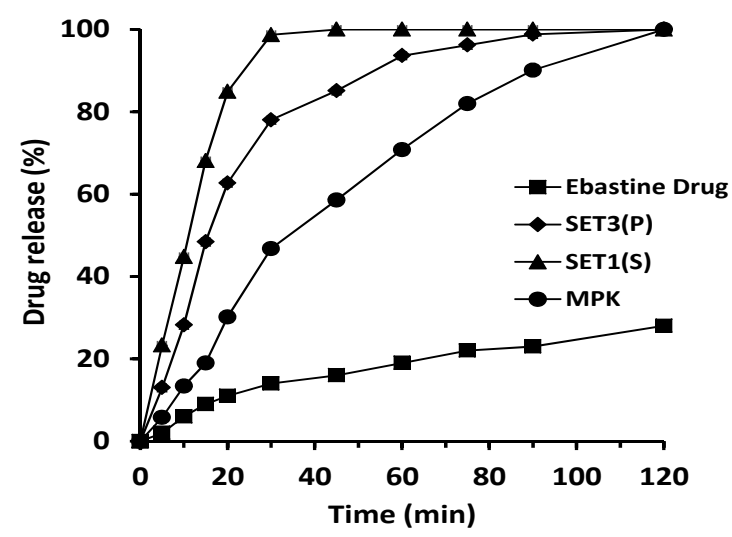

Figure 3: In vitro release studies of pure drug, SDFDT and MPK (a commercial product).

Trop J Pharm Res, September 2020; 19(9): 1801 


\section{FTIR spectra}

The FTIR scans of ebastine, physical mixture, solid dispersion and SD-FDT in the range of 400 to $4000 \mathrm{~cm}^{-1}$ are shown in Figure 4.

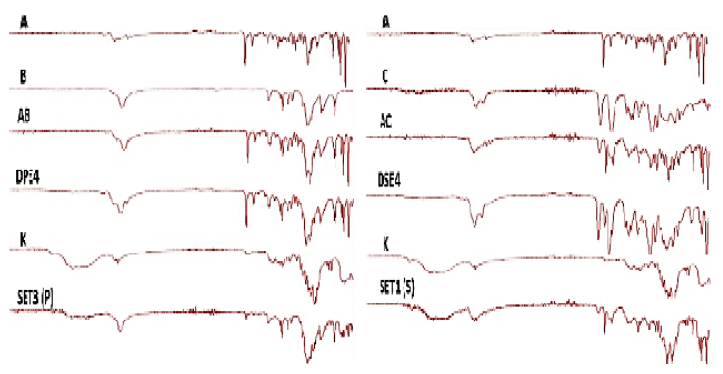

Figure 4: FTIR of (A) drug, (B) poloxamer 188, (C) soluplus, $(A B)$ physical mixture of drug and poloxamer 188, (AC) physical mixture of drug and soluplus, (DPE4) solid dispersion of poloxamer and EBT, (DSE4) solid dispersion of soluplus and EBT, (K) blend of tablet excipients, (SET1(S)) fast disintegrating tablet containing soluplus SD, (SET3 (P)) fast disintegrating tablet containing poloxamer SD

\section{Crystalline properties}

The x-ray diffractograms show crystalline peaks of pure drug between 0 to $45^{\circ}$, however, these peaks were not present in the formulations prepared with soluplus SET1(S) and poloxamer 188 SET3 $(P)$ depicting conversion into amorphous form (Figure 5).

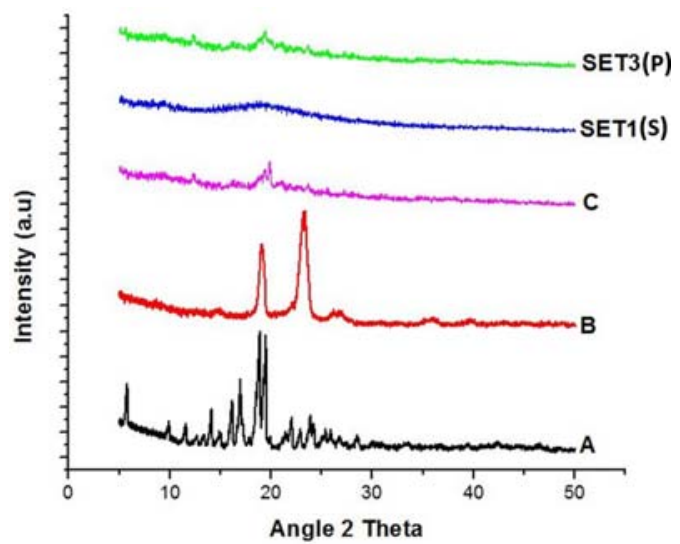

Figure 5: X-ray diffractogram of (A) drug (B) poloxamer $188(\mathrm{C})$ soluplus, (SET1(S)), SD-FDT with soluplus, (SET3 (P)), SD-FDT with poloxamer 188

\section{Thermal properties}

Ebastine exhibited its endothermic peak near 90 ${ }^{\circ} \mathrm{C}$ (Figure 6). The melting peak in the prepared formulations (SET1(S), (SET3 (P) was shifted towards left side which could be attributed due to formation of amorphous solid dispersion.

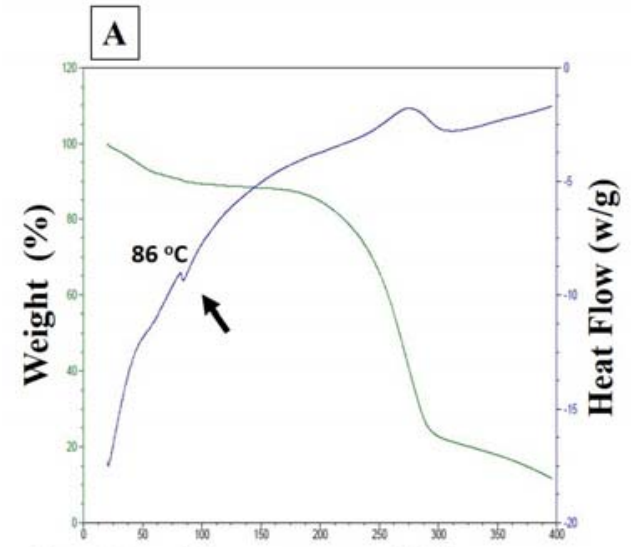

Exo Up Temperature $\left({ }^{\circ} \mathrm{C}\right)$

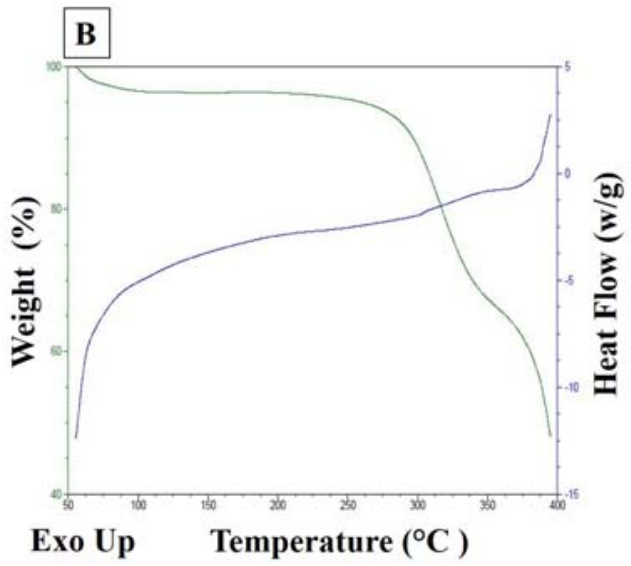

Figure 6: (A) DSC and TGA of pure drug and formulation (SET1(S) SD-FDT with soluplus

\section{Morphological characteristics}

The SEM results of ebastine before and after processing are presented in figure 7 . The physical inspection showed round but little irregular surface of particles.

\section{DISCUSSION}

The published bioavailability of ebastine is approximately $1 \%$ which clearly indicates its low solubility. In order to increase the therapeutic effectiveness of ebastine, significantly enhanced bioavailability is required, which could likely be accomplished by increasing its solubility [19]. Appropriate solubilizing agents were chosen for the preparation of ebastine solid dispersions after initial screening. Determined saturated ebastine solubility in distilled water was very low. The theoretical output of solubilizing agents/ excipients on ebastine solubility, poloxamer 188, soluplus and oleic acid have been identified for further study. The ebastine solubility was approximately enhanced 5-fold with poloxamer 
188 and 20-fold with soluplus, respectively. On the other side, the solubility of ebastine was just marginally increased in coconut oil, castor oil, spans and tween 20 and thus not considered for further studies.
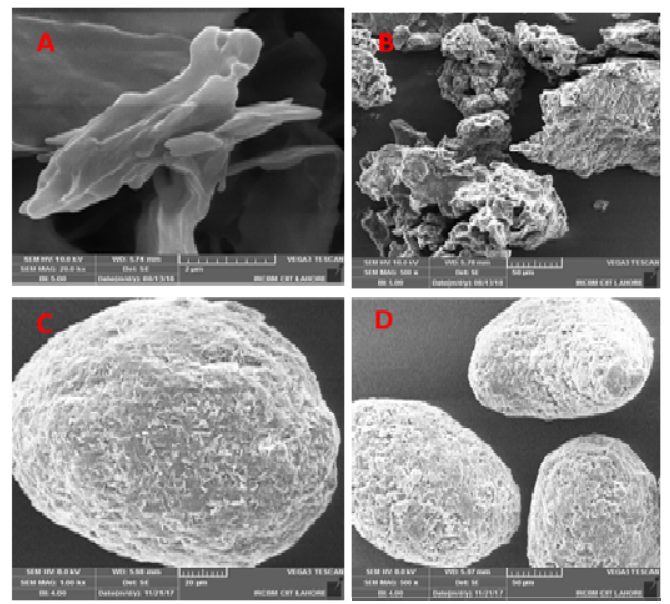

Figure 7: SEM photograph of $(A)$ drug $(B)$ physical mixture, (C) DPE4 and (D) DSE4

The physiochemical properties of the excipients and the mixing time have influenced the solubility of ebastine. Providing higher mixing time during the preparation of solid dispersion resulted in sticky mass which consequently had a negative impact on solubility. Similarly, higher concentrations of tween 80 and oleic acid culminated in the development of tacky lumps during the processing of solid dispersions. The soluplus SDs were more free-flowing than the poloxamer SDs. Furthermore, SDs formulated using a 1:1 ratio of drug to carrier (poloxamer 188 and soluplus) demonstrated favorable effects in solubility enhancement. The developed SDs are combined with bulk powder of tablets and compressed into SD-FDT by direct compression without any challenge [20].

It was noticed that the saturated solubility of ebastine from the produced SD-FDT is higher relative to the pure drug. Solid dispersion of poloxamer 188 improved ebastine solubility by 5fold. It may be because the thick hydrophobic tail of poloxamer 188 stabilized the dispersion via a steric system [21]. Particle agglomeration was reduced due to the presence of electrostatic repulsion of non-ionic emulsifiers, such as poloxamer-188 [22].

It was found that with a change in the concentration of solubilizers (poloxamer188 and soluplus) the solubility of ebastine was changed proportionately [23]. Higher concentration of solubilizers improved the solubility and dissolution rate of ebastine many folds. This could be linked to a reduction in the size of the drug particles, which could potentially increase the fluidity of the interface and reduce the interfacial tension of the prepared system [24]. Importantly, soluplus displayed more positive findings relative to other solubilizers (poloxamer 188, tween 80) used in our experiments. The higher dissolution rate of ebastine from the developed SD-FDT could be due to the combined effects of incorporating solid dispersion and super-disintegrants into SD-FDT. This may be inferred from the results that the mixture of appropriate solubilizing agents and super-disintegrants had a drastic impact on the solubility of ebastine [25].

The FTIR spectra of pure ingredients and developed SD-FDT were almost the same, displaying no significant changes in peaks that suggested strong drug and excipient compatibility. The DSC data shows a high endothermic melting peak of ebastine near $86^{\circ} \mathrm{C}$ while this peak is moved downward in the DSC physical mixture thermograph and formulated SDs (Figure 6) which is an indicator of drug transfer to amorphous form. The rise in ebastine solubility and dissolution rates may also be accompanied by a decrease in melting enthalpies [26]. Furthermore, it is obvious from the XRD study of pure drugs, solubilizers and SD-FDT that the crystallinity of ebastine decreased in SD formulations. The SEM study also showed that the pure drug changed its particle shape and converted into a circular form after processing. The developed tablets were successfully optimized using central composite rotatable design. Dissolution rate of EBT in solid dispersion loaded fast disintegrating tablets (SET1(S) was significantly higher than the dissolution rate of all other formulations. The drug release pattern produced by SD-FDT and the commercial ebastine brand indicated that the release rate from our formulated SD-FDT was fairly high.

\section{CONCLUSION}

The findings of this work reveal that selecting appropriate solubilizers for a solid dispersion and super-disintegrants for SD-FDT synergistically enhances the solubility and dissolution rate of ebastine. Solid dispersions with high ebastine solubility are efficiently incorporated into the formulations of SD-FDT. Decreased crystallinity and ebastine particle size largely account for the amplification of dissolution. Thus, the optimized ebastine loaded SD-FDT has potential application in the production of ebastine formulations with enhanced bioavailability.

Trop J Pharm Res, September 2020; 19(9): 1803 


\section{DECLARATIONS}

\section{Acknowledgement}

The authors are thankful to Apsis Pharmaceuticals, Gunjranwala, Pakistan for providing chemicals and lab facilities for this research work.

\section{Conflict of interest}

No conflict of interest is associated with this work.

\section{Contribution of authors}

We declare that this work was done by the authors named in this article and all liabilities pertaining to claims relating to the content of this article will be borne by the authors.

\section{Open Access}

This is an Open Access article that uses a funding model which does not charge readers or their institutions for access and distributed under the terms of the Creative Commons Attribution License (http://creativecommons.org/licenses/by/ 4.0) and the Budapest Open Access Initiative (http://www.budapestopenaccessinitiative.org/rea d), which permit unrestricted use, distribution, and reproduction in any medium, provided the original work is properly credited.

\section{REFERENCES}

1. Kassem MA, EIMeshad AN, Fares AR. Enhanced solubility and dissolution rate of lacidipine nanosuspension: Formulation via antisolvent sonoprecipitation technique and optimization using boxbehnken design. AAPS PharmSciTech 2017; 18(4): 983-996.

2. Rane SS, Anderson BD. What determines drug solubility in lipid vehicles: Is it predictable? Adv Drug Del Rev 2008; 60(6): 638-656.

3. Deshpande TM, Shi H, Pietryka J, Hoag SW, Medek A. Investigation of polymer/surfactant interactions and their impact on itraconazole solubility and precipitation kinetics for developing spray-dried amorphous solid dispersions. Mol Pharm 2018; 15(3): 962-974.

4. Shekunov B, Montgomery ER. Theoretical analysis of drug dissolution: I. Solubility and intrinsic dissolution rate. J Pharm Sci 2016; 105(9): 2685-2697.

5. An J-H, Lim C, Kiyonga AN, Chung IH, Lee IK, Mo $K$, Park M, Youn W, Choi WR, Suh Y-G. Co-amorphous screening for the solubility enhancement of poorly water-soluble mirabegron and investigation of their intermolecular interactions and dissolution behaviors. Pharmaceutics 2018; 10(3): 149.

6. Tran P, Pyo Y-C, Kim D-H, Lee S-E, Kim J-K, Park J-S. Overview of the manufacturing methods of solid dispersion technology for improving the solubility of poorly water-soluble drugs and application to anticancer drugs. Pharmaceutics 2019; 11(3): 132.

7. Tambe A, Pandita N. Enhanced solubility and drug release profile of boswellic acid using a poloxamerbased solid dispersion technique. J Drug Deliv Sci Technol 2018; 44: 172-180.

8. Cagel M, Tesan FC, Bernabeu E, Salgueiro MJ, Zubillaga MB, Moretton MA, Chiappetta DA. Polymeric mixed micelles as nanomedicines: Achievements and perspectives. Eur J Pharm Biopharm 2017; 113: 211 228.

9. Baghel S, Cathcart H, O'Reilly NJ. Polymeric amorphous solid dispersions: A review of amorphization, crystallization, stabilization, solid-state characterization, and aqueous solubilization of biopharmaceutical classification system class ii drugs. J Pharm Sci 2016; 105(9): 2527-2544.

10. Van Cauwenberge $P$, De Belder T, Sys L. A review of the second-generation antihistamine ebastine for the treatment of allergic disorders. Expert Opin Pharmacother 2004; 5(8): 1807-1813.

11. Luo Y, Chen D, Ren L, Zhao X, Qin J. Solid lipid nanoparticles for enhancing vinpocetine's oral bioavailability. J Controlled Release 2006; 114(1): 5359.

12. Nanaki S, Eleftheriou RM, Barmpalexis $P$, Kostoglou M, Karavas E, Bikiaris D. Evaluation of dissolution enhancement of aprepitant drug in ternary pharmaceutical solid dispersions with soluplus ${ }^{\circledR}$ and poloxamer 188 prepared by melt mixing. Sci 2019; 1(2): 48.

13. Soni LK, Narsinghani T, Saxena C. UVspectrophotometric estimation of ebastine and phenylephrine hydrochloride in tablet dosage form using absorption ratio method. Der Pharmacia Sinica 2011; 2(6): 11-16.

14. Baka E, Comer JE, Takács-Novák K. Study of equilibrium solubility measurement by saturation shake-flask method using hydrochlorothiazide as model compound. J Pharm Biomed Anal 2008; 46(2): 335-341.

15. Passerini N, Albertini B, González-Rodríguez ML, Cavallari C, Rodriguez L. Preparation and characterisation of ibuprofen-poloxamer 188 granules obtained by melt granulation. Eur J Pharm Sci 2002; 15(1): $71-78$.

16. Modi A, Tayade P. Enhancement of dissolution profile by solid dispersion (kneading) technique. AAPS PharmSciTech 2006; 7(3): E87.

17. Schiermeier S, Schmidt PC. Fast dispersible ibuprofen tablets. Eur J Pharm Sci 2002; 15(3): 295-305.

18. Rus LM, Tomuta I, luga C, Maier C, Kacso I, Borodi G, Bratu I, Bojita M. Compatibility studies of 
indapamide/pharmaceutical excipients used in tablet preformulation. Farmacia 2012; 60(1): 92-101.

19. Mahajan VR, Basarkar GD. Development of self microemulsifying drug delivery system of ebastine by spray drying technology: Characterization, in-vitro and in-vivo evaluation. Thai Journal of Pharmaceutical Sciences (TJPS) 2019.

20. Mohamed MS, Abdelhafez WA, Zayed G, Samy AM. In vitro and in vivo characterization of fast dissolving tablets containing gliquidone-pluronic solid dispersion. Drug Dev Ind Pharm 2019; 45(12): 1973-1981.

21. Kolašinac N, Kachrimanis K, Homšek I, Grujić B, Đurić Z, Ibrić S. Solubility enhancement of desloratadine by solid dispersion in poloxamers. Int J Pharm 2012; 436(1-2): 161-170.

22. Wei C-C, Ge Z-Q. Influence of electrolyte and poloxamer 188 on the aggregation kinetics of solid lipid nanoparticles (sIns). Drug Dev Ind Pharm 2012; 38(9): 1084-1089.
23. Tanaka Y, Kubota A, Matsuo A, Kawakami A, Kamizi H, Mochigoe A, Hiramachi $T$, Kasaoka S, Yoshikawa $H$, Nagata S. Effect of absorption behavior of solubilizers on drug dissolution in the gastrointestinal tract: Evaluation based on in vivo luminal concentration-time profile of cilostazol, a poorly soluble drug, and solubilizers. J Pharm Sci 2016; 105(9): 2825-2831.

24. Ma J, Song X, Luo J, Zhao T, Yu H, Peng B, Zhao S. Molecular dynamics simulation insight into interfacial stability and fluidity properties of microemulsions. Langmuir 2019; 35(42): 13636-13645.

25. Meruva S, Thool P, Gong Y, Karki S, Bowen W, Kumar S. Role of wetting agents and disintegrants in development of danazol nanocrystalline tablets. Int $\mathrm{J}$ Pharm 2020; 577: 119026.

26. Hussain A, Smith G, Khan KA, Bukhari NI, Pedge NI, Ermolina I. Solubility and dissolution rate enhancement of ibuprofen by co-milling with polymeric excipients. Eur J Pharm Sci 2018; 123: 395-403. 